\title{
Guest Editor's Note
}

THIS ISSUE PRESENTS a selection of papers from the 51st RBMS Preconference, entitled Join or Die: Collaboration in Special Collections. From the beginning, the intention of the preconference planners was to reflect that theme not just in the substance of the programming but in the structure of the conference itself, with a schedule that emphasized more diverse and interactive forms of programming. That idea has been carried through to this special issue - three of the four articles were originally presented as part of seminars. I am grateful to the authors for their willingness to go beyond the already considerable effort they put into their talks to prepare them for publication here.

Necessarily, this issue contains only a small portion of what was presented at the preconference. We were, however, able to record all three plenaries, two panels of case studies, and ten seminars. Those recordings are available on the section Web site at http://rbms.info/conferences/preconfdocs/2010/2010docs.shtml.

As my predecessor Arvid Nelsen so aptly noted in his introduction to last year's preconference issue, serving as the Program Chair is "a terrifying honor" and a task that requires the indispensable assistance of many colleagues. I am very glad to have one more opportunity to thank the members of the Program Planning, Local Arrangements, and Seminars Committees for their indefatigable work to make the preconference a success. Likewise, lest the honorary title of "Guest Editor" confuse anyone, I want to thank RBM Editor Beth Whittaker for turning my suggestions into the issue you hold in your hands.

John Overholt Assistant Curator

The Donald and Mary Hyde Collection of Dr. Samuel Johnson/

Early Modern Books and Manuscripts

Houghton Library

Harvard University 